Villalba, J. A., Latus, M., Hamilton, S., \& Kendrick, C. (2005). School counselors' knowledge

of functional behavioral assessments. Behavioral Disorders, 30, 445-451.

\title{
School Counselors' Knowledge of Functional Behavioral Assessments
}

$\star \star \star$ Reprinted with permission. No further reproduction is authorized without written permission from Council for Children with Behavioral Disorders. This version of the document is not the version of record. Figures and/or pictures may be missing from this format of the document.*** José A. Villalba The University of North Carolina at Greensboro

\author{
Maryann Latus, Stacie Hamilton, and Colleen Kendrick \\ Indiana State University
}

ABSTRACT: A functional behavioral assessment (FBA) is one of the tools used by school personnel for providing a fair educational experience for students in special education programs. Although several school counselors are expected to participate in school-level FBA teams, questions arise as to their level of awareness, training, and beliefs regarding FBA procedures and practices. For this study, practicing school counselors were surveyed in order to determine their awareness, knowledge, and role in the $F B A$ process.

School counselors are a vital part of school children's scholastic experience, assisting them with a variety of academic and personal-social developmental tasks (Schmidt, 2003). This point is illustrated in the level and variety of involvement by school counselors with all children and in various settings, including their work with students with disabilities in their schools. According to the Individuals with Disabilities Education Act (IDEA), school counseling services must be made available to all students in special education programs as part of their right to a free and appropriate public education (Bowen \& Glenn, 1998; Clark, 1998). Furthermore, IDEA mandates that each child who is eligible for a special education program and displays inappropriate behaviors must have a functional behavioral assessment (FBA) on record, developed by a team of school service providers, including school counselors (Jolivette, Barton-Arwood, \& Scott, 2000). Therefore, if school counselors are expected to take an active role in the educational and personal-social well-being of students in special education programs, and if federal law requires that children in special education programs who display inappropriate behavior have an FBA as part of their individual education plan (IEP), then school counselors' role and awareness of FBA must be addressed.

FBAs are tools used by educators, social workers, psychologists, and mental health professionals to establish antecedents and causes of children's inappropriate, problematic, and/or violent behaviors. With regard to children enrolled in special education programs, information is collected about the individuals in question through observations and interviews with their parents, teachers, and other adults responsible for the care of these children (Conroy \& Davis, 2000; Drasgow, Yell, Bradley, \& Shriner, 1999). Consequently, the indirect goal of service providers engaged in the information-gathering process of $\mathrm{FBA}$ is to establish ways to reduce negative actions or reactions, while seeking to increase more appropriate actions. Once information has been gathered and strategies for increasing desired behaviors have been determined, the FBA is used to establish a behavioral intervention plan (BIP) (Jolivette et al,, 2000). The BIP is implemented on occasions when children in question act or react in an inappropriate manner that may impede their academic and personal-social success, or that of other children in the school. According to Jolivette et al., all members involved in the development of the $F B A$ are responsible for effectively using the BIP. The overall goal of an FBA and a BIP is to provide short-term and long-term benefits to those children who appear to get into trouble often, have problems interacting with their peers, or react violently to certain antecedents (Conroy, Clark, Gable, \& Fox, 1999; Gable, 
1999). Finally, research studies have shown that a properly orchestrated FBA leads to decreases in inappropriate and disruptive behaviors for children who have received an FBA and who have an active BIP (Conroy et al., 2001; Scott \& Nelson, 1999).

Carpenter, King-Sears, and Keys (1998) advocated for school counselors' participation in interdisciplinary teams working with children with exceptionalities in an effort to address the psychosocial development of these children, which may be overlooked by educators focused on academic goals. According to several researchers (Conroy et al., 2001; Jolivette et al., 2000; Rogers, 2001; Scott \& Nelson, 1999), an FBA should be carried out by interdisciplinary teams composed of various school and related personnel. Membership in an FBA team varies from school to school, and from school district to school district. Members are usually chosen based on their familiarity with special education procedures, child development, and behavioral modification techniques (Jolivette et al.). Functional behavioral assessment teams typically are made up of a regular education teacher, a special education teacher, a school psychologist, and an administrator, in addition to other school personnel such as a speechlanguage pathologist and school counselors (Rogers). As part of the FBA process, team members take on specific responsibilities such as observing the student, filling out behavioral checklists, communicating with parents, etc (Rogers). However, based on the first and second authors' professional experiences as school counselors, in addition to their information communications with other practicing school counselors, most school counselors are not familiar with FBA and BIP procedures.

In the only study to report the experiences of counselors and the FBA process, Lane (2002) reported most counselors lack specific expertise and knowledge of FBA procedures or their roles on FBA teams prior to serving on their first FBA team. Furthermore, she established that only $29.5 \%$ of her sample used FBA. Finally, upon further review of the literature in scholarly publications (Behavioral Disorders, Professional School Counseling and the fournal for Counseling and Development) related to school counselors and FBA since 1995, the authors did not find specific articles specifically addressing school counselors' role in FBA. Therefore, the authors attempted to survey school counselors to determine their roles on FBA teams, where they learned about $\mathrm{FBA}$, and their experiences in $\mathrm{FBA}$ procedures, as well as general special education knowledge.

\section{Determining School Counselors' Awareness and Role Regarding Functional Behavioral Assessment}

The need to make FBA more effective and relevant in the educational setting is directly related to the reauthorization of IDEA in 1997 (Gable, 1999). Since most school counselors are responsible for some portion of the special education referral process (educational planning team member, orchestrating the special education testing procedures, member of the staffing committee, member of the individual educational planning team, etc.) (Carpenter, King-Sears, \& Keys, 1998), it is reasonable to expect school counselors to understand how to engage in the FBA process. Due to the paucity of research on school counselors and the FBA process, the authors developed and distributed a survey to address the school counselor's role and knowledge of FBA (see Appendix 1).

\section{Method}

\section{Participants}

Out of a total of 1,791 school counselors who were mailed a survey, 527 responded, which represents a response rate of $29 \%$. Participants were certified school counselors from one Midwestern state. Participants' educational settings were fairly equally divided, with $31.7 \%(n=167)$ of respondents reporting they were elementary school counselors, $28.7 \%(n=151)$ indicating they were middle school counselors, and $39.7 \%(n=209)$ were high school counselors. Thirty-three percent in $=174$ ) of participating school counselors had no previous experience as a teacher prior to being school counselors. On a related note, $89.2 \%(n=470)$ of the respondents had no experience as a special education teacher. As for years of experience, $63.2 \%$ of the sample had 11 or fewer years experience as a school counselor. Finally, $90.7 \%$ of the sample had a master's degree in school counseling, with all but $1 \%$ of the remaining respondents equally 
Demographic Information (please CHECK ONE choice per item):
(A) Educational Setting: () Elementary School
() Middle/Junior High School
() High School
(B) Highest Degree Earned: $\cup$ Bachelor's Degree
$\cup$ Master's Degree

\author{
U Specialist Degree \\ U Doctorate Degree
}

(C) Years as a School Counselor:
U $0-3$ years
U) $12-15$ years
U) $16-19$ years
(1) $4-7$ years
(U) 20 or more years
(1) $8-11$ years
(D) Are You a National Certified Counselor?
UYes
U) No

(E) Experience as a Licensed Teacher Prior to Becoming a School Counselor:

() None U) Elementary Teacher (grades PK-5) U) Secondary Teacher (grades 6-12)

(f) Experience as a Licensed Special Education Teacher Prior to Becoming a School Counselor;

$\cup$ None U Elementary Teacher (grades PK-5) USecondary Teacher (grades 6-12)

Please answer each of the following questions regarding Functional Behavioral Assessments (FBA). Please indicate one answer per question by circling your choice. Answer each question from your CURRENT perspective, based on your present employment and educational setting (elementary, middle/junior, or high school).

1. Are you comfortable with your level of knowledge regarding FBA?

$\begin{array}{lll}\text { Yes } & \text { No } & \text { Und } \\ \text { Yes } & \text { No } & \text { Und } \\ \text { Yes } & \text { No } & \text { Und } \\ \text { Yes } & \text { No } & \text { Und } \\ \text { Yes } & \text { No } & \text { Und } \\ \text { Yes } & \text { No } & \text { Und } \\ \text { Yes } & \text { No } & \text { Und } \\ \text { Yes } & \text { No } & \text { Und } \\ \text { Yes } & \text { No } & \text { Und } \\ \text { Yes } & \text { No } & \text { Und } \\ \text { Yes } & \text { No } & \text { Und }\end{array}$

2. Would you like to increase your level of knowledge regarding FBA?

A ?

3. Have you had any formal training in conducting $F B A$ ?

4. Did you learn about FBA in a school counseling graduate program?

5. Have you attended any FBA workshops/conference presentations?

6. Does your school have an FBA team?

7. Are you part of your school's FBA team?

8. Do you have a well-defined role on your school's FBA team?

9. Is it the responsibility of a school counselor to be on an FBA team?

10. Should a school counselor be leading/conducting an FBA team?

11. Are school counselors at your school responsible for managing/ organizing the special education identification and referral process?

12. Does every child in a special education program at your school have an FBA?

13. Are FBAs mandated by the Individuals with Disabilities Education Act?

14. Is the information rendered by an FBA useful to school counselors?

Yes No Und
Yes No Und

15. You have participated or assisted on how many FBA teams? (Please choose 1 answer.)
$\cup 0$
U) $1-10$
(U) 11-20
บ 21-30
U) $31-40$
( $) 41$ or more 
distributed between having a bachelor's degree or a specialist's degree.

\section{Instrument}

The survey (see Appendix 1) was created by the researchers using information gathered from the review of literature, as well as personal experiences with $\mathrm{FBA}$ activities in the school setting (Carpenter et al., 1998; Conroy et al., 2001; Jolivette et al., 2000; Lane, 2002; Rogers, 2001). Content validity for the survey was established by sharing the questionnaire with two counselor education colleagues and three practicing school counselors (one from each level). The five external reviewers were asked to critique the 15-item survey, with specific focus on the relevance, wording, and order of the items. Due to their recommendations, some survey items were shortened in order to read more clearly and reduce confusing verbiage, and three questions related to general special education knowledge were added. Also, the possible responses for the first 14 survey items were changed from "yes," "no," "maybe," to "yes," "no," "undecided."

\section{Results}

Frequency distributions and demographic differences yielded some interesting results. With regard to FBA knowledge, a majority of elementary, middle, and high school counselors who responded to the survey reported they had not learned about FBA in their graduate training programs, nor had they attended FBA workshops or received formal FBA training. Consequently, a slight majority indicated they were not comfortable with their FBA knowledge and would like to increase their knowledge. Also, a slight majority of respondents indicated their schools did not have a defined FBA team. However, those school counselors who indicated they had an FBA team in their schools reported they had a well-defined role on that team. In addition, there was some confusion in the sample as to whether school counselors should be conducting school FBA teams, regardless of whether their school had an FBA team or not. Furthermore, responses to the special education questions indicated a majority of respondents were in charge of their school's special education program. Finally, elementary and middle school counselors in the survey expressed greater experience working on FBA teams than participating high school counselors. For a more detailed description of survey results, please see Table 1.

Preliminary chi-square analysis was conducted to determine if demographic information was related to how respondents completed the survey. Of the six independent variables listed in the demographic portion of the survey, the most common and significant relationships occurred between the respondents' work settings and their survey responses. Specifically, analysis showed that respondents' answers to all but three questions ("Are you comfortable with your level of knowledge regarding FBA?"; "Have you had any formal training in conducting FBA?"; and "Are FBAs mandated by the Individuals with Disabilities Education Act?") was connected to their position as an elementary, middle, or high school counselor.

\section{Discussion}

Since the sample size, response rate, and geographic location of the sample are limited, caution must be taken when considering these results. Overall, it appears that survey respondents feel their knowledge and preparation of the FBA process has been inadequate. Furthermore, pre-service and professional development has been lacking in the area of FBA. Consistent with other counselors surveyed on their FBA knowledge (Lane, 2002), the majority of respondents would be interested in learning more about FBA, even though most of them do not serve on their school's FBA team. Also, respondents seemed somewhat undecided as to their responsibilities on FBA teams and, in general, special education knowledge. This is particularly relevant considering the majority of the sample was responsible for managing organizing the special education identification and referral process. Finally, the relationship between how school counselors responded to the survey appears to be related to their work setting, signifying some school counselors' FBA experiences and knowledge may be related to their placement in elementary, middle, or high schools.

Aside from the study limitations already discussed, a few other shortcomings must be highlighted. First, since the survey was designed to take as little time from the school 
Table 1

Frequencies and Percentages of School Counselors' Responses Based on Educational Settings

Settings

\section{Educational Setting}

Yes

No

Undecided

Total

Are you comfortable with your level of knowledge regarding FBA?

Elementary $\quad 57(34 \%) \quad 88(53 \%)$

Middle $\quad 48(32 \%) \quad 79(52 \%)$

High $\quad 60(29 \%) \quad 124(59 \%)$

Would you like to increase your level of knowledge regarding FBA?

$\begin{array}{lllll}\text { Elementary } & 139(83 \%) & 17(10 \%) & 11(7 \%) & 167 \\ \text { Middle } & 110(73 \%) & 24(16 \%) & 17(11 \%) & 151 \\ \text { High } & 139(67 \%) & 38(18 \%) & 32(15 \%) & 209\end{array}$

High

$139(67 \%)$

$38(18 \%)$

209

Have you had any formal training in conducting FBA?

Elementary

Middle

$50(29 \%)$

$44(29 \%)$

$115(69 \%)$

$38(18 \%)$

$104(69 \%)$

$2(2 \%)$

167

High

$166(79 \%)$

151

Did you learn about FBA in a school counseling graduate program?

Elementary - $17(10 \%) \quad 150(90 \%)$

Middle

$12(8 \%)$

$138(91 \%)$

$3(2 \%)$

209

High

$32(15 \%)$

$167(80 \%)$

167

Have you attended any FBA workshops/conference presentations?

Elementary

$54(32 \%)$

$48(32 \%)$

$112(67 \%)$

Middle

$36(17 \%)$

$102(68 \%)$

High

$172(82 \%)$

$0(0 \%)$

151

$1(1 \%)$

209

Does your school have an FBA team?

$\begin{array}{ll}\text { Elementary } & 67(40 \%) \\ \text { Middle } & 59(39 \%) \\ \text { High } & 57(27 \%)\end{array}$

$57(27 \%)$

$90(54 \%)$
$78(52 \%)$
$126(60 \%)$

$10(6 \%)$

167

High

$126(60 \%)$

$(9 \%)$

151

209

Are you part of your school's FBA team?

$\begin{array}{ll}\text { Elementary } & 67(40 \%) \\ \text { Middle } & 44(29 \%) \\ \text { High } & 38(18 \%)\end{array}$

$89(53 \%)$

$90(60 \%)$

$160(77 \%)$

$11(7 \%)$

167

151

209

Do you have a well-defined role on your school's FBA team?

Elementary

$53(32 \%)$

$31(21 \%)$

$102(61 \%)$

$104(69 \%)$

$17(11 \%)$

167

151

Middle

$31(15 \%)$

$157(75 \%)$

$12(7 \%)$

167

$16(10 \%)$

151

$21(10 \%)$

209

Is it the responsibility of a school counselor to be on an FBA team?
Elementary
$83(50 \%)$
$52(31 \%)$

$61(40 \%)$

$62(41 \%)$

$32(19 \%)$

167

Middle

$51(24 \%)$

$101(48 \%)$

$28(19 \%)$

151

High

$42(25 \%)$

$23(15 \%)$

$43(25 \%)$

$82(50 \%)$

167

Elementary

$17(8 \%)$

$54(36 \%)$

$74(49 \%)$

151

High

$94(45 \%)$

$98(47 \%)$

209

Are school counselors at your school responsible for managing/organizing the special education identification and referral process?

\begin{tabular}{lcccr} 
Elementary & $87(52 \%)$ & $76(46 \%)$ & $4(2 \%)$ & 167 \\
Middle & $114(75 \%)$ & $33(22 \%)$ & $4(3 \%)$ & 151 \\
High & $99(47 \%)$ & $94(45 \%)$ & $16(8 \%)$ & 209 \\
\hline
\end{tabular}




\begin{tabular}{|c|c|c|c|c|c|c|}
\hline $\begin{array}{l}\text { Settings } \\
\text { Educational Setting }\end{array}$ & Yes & & No & \multicolumn{2}{|r|}{ Undecided } & Total \\
\hline \multicolumn{7}{|c|}{ Does every child in a special education program at your school have an FBA? } \\
\hline Elementary & $16(10 \%)$ & & $124(74 \%)$ & \multicolumn{2}{|r|}{$27(16 \%)$} & 167 \\
\hline Middle & $21(14 \%)$ & & $106(70 \%)$ & \multicolumn{2}{|r|}{$24(16 \%)$} & 151 \\
\hline High & $27(13 \%)$ & & $110(53 \%)$ & \multicolumn{2}{|r|}{$72(34 \%)$} & 209 \\
\hline \multicolumn{7}{|c|}{ Are FBAs mandated by the Individuals with Disabilities Education Act? } \\
\hline Elementary & $35(21 \%)$ & & $36(22 \%)$ & \multicolumn{2}{|r|}{$96(57 \%)$} & 167 \\
\hline Middle & $35(23 \%)$ & & $35(23 \%)$ & \multicolumn{2}{|r|}{$81(54 \%)$} & 151 \\
\hline High & $49(23 \%)$ & & $37(18 \%)$ & \multicolumn{2}{|r|}{$123(59 \%)$} & 209 \\
\hline \multicolumn{7}{|c|}{ Is the information rendered by an FBA useful to school counselors? } \\
\hline Elementary & $115(69 \%)$ & & $5(3 \%)$ & \multicolumn{2}{|r|}{$47(28 \%)$} & 167 \\
\hline Middle & $96(64 \%)$ & & $6(4 \%)$ & \multicolumn{2}{|r|}{$49(32 \%)$} & 151 \\
\hline High & $93(44 \%)$ & & $12(6 \%)$ & \multicolumn{2}{|r|}{$104(50 \%)$} & 209 \\
\hline \multicolumn{7}{|c|}{ You have participated or assisted on how many FBA teams? } \\
\hline none & $0-10$ & $11-20$ & $21-30$ & $31-40$ & 41 or more & Total \\
\hline Elementary & $58(35 \%)$ & $18(11 \%)$ & $8(5 \%)$ & $2(1 \%)$ & $10(6 \%)$ & 167 \\
\hline $63(42 \%)$ & $52(34 \%)$ & $17(11 \%)$ & $9(6 \%)$ & $2(1 \%)$ & $8(5 \%)$ & 151 \\
\hline $136(65 \%)$ & $44(21 \%)$ & $16(8 \%)$ & $4(2 \%)$ & $2(1 \%)$ & $7(3 \%)$ & 209 \\
\hline
\end{tabular}

counselor's schedule as possible, potentially helpful information was not gathered, such as what role the school counselor performed on their school's FBA team, why their school did not have an FBA team, what were the college courses in which they learned about FBA, or how they felt about coordinating/not coordinating special education programs in their school. Also, it would have been interesting if respondents who had participated in the FBA process were provided the opportunity to describe those experiences, but the survey did not request that kind of information. However, the authors believe the cursory information on school counselors' knowledge of the FBA process and their roles in FBA teams is a first step toward addressing the need for more research in the area.

School counselors are expected to take on more administrative, consultative, and advocacy roles than ever before (American School Counselor Association, 2003). Their pre-service training in assessment, facilitative communication, consultation, and human development enables them to work in a variety of capacities within their schools. Since more and more school counselors are performing a direct and administrative role in the special education process within their schools (Clark, 1998; Villalba \& Sheperis, 2004), they are positioned to be active members of school
FBA teams. The overall assumption that may be drawn from the results of this survey is that participating school counselors have not learned about FBA prior to entering their school counseling positions, yet some have responsibilities within their school's FBA teams and many more are directly involved in special education procedures in their schools. Considering the relationship between special education and the FBA process, it would not be farfetched to expect school counselors with roles in special education procedures to also be knowledgeable of FBA. In short, school counselors should be more actively involved in the FBA process, and their pre-service training should contain adequate FBA preparation.

\section{Conclusion}

Due to the IDEA legislation and school counseling standards, measures must be taken to increase the FBA knowledge of school counseling students and professional school counselors American School Counselor Association, 2003; Bowen \& Glenn, 1998; Clark, 1998). Therefore, school counselors need more exposure to the FBA process if they are to be more effective and meet the needs of all children (Carpenter et al. 1998). This study, in spite of its limitations, calls attention 
to the respondents' lack of information and training in FBA. The authors are aware that counselor educators may not be familiar with FBA procedures or processes. Consequently, it may be necessary for counselor education departments to collaborate with special education departments within their institutions in order to ensure proper school counselor preparation. Also, school counselors in the field who are in need of FBA knowledge and skills may wish to communicate with colleagues more knowledgeable of the FBA process. Finally, it is the hope of the authors that further studies in the area will lead to better-trained school counselors, increasingly capable of addressing the needs of all children.

\section{REFERENCES}

American School Counselor Association (2003). The ASCA national model: A framework for school counseling programs. Alexandria, VA: Author

Bowen, M. L., \& Glenn, E. E. (1998). Counseling interventions for students who have mild disabilities. Professional School Counseling, 2, 16-25.

Carpenter, S. L., King-Sears, M. E., \& Keys, S. G. (1998). Counselors + educators + families as a transdisciplinary team $=$ more effective inclusion for students with disabilities. Professional School Counseling, 2, 1-15.

Clark, J. P. (1998). Functional behavioral assessment and behavioral intervention plans: implementing the student discipline provisions of IDEA 1997. A technical assistance guide for school social workers. School Social Work Association of America, Washington, DC. (ERIC Document Reproduction Service No. ED455632).

Conroy, M., Clark, D., Gable, R. A., \& Fox, J. (1999). A look at the IDEA discipline provisions: Implications for change in the roles and responsibilities of school personnel. Preventing School Failure, 43, 64-70.

Conroy, M. A., \& Davis, C. A. (2000). Early elementary-aged children with challenging behaviors: Legal and educational issues related to IDEA and assessment. Preventing School Failure, 44, 163-168.

Conroy, M., Fox, J., Gable, R., Quinn, M., Ruterford, R., \& Van Acker, R. (2001). Putting quality functional assessment into practice in schools: $A$ research agenda on behalf of $E / B D$ students. Education and Treatment of Children, 24, 261275.
Drasgow, E., Yell, M. L., Bradley, R., \& Shriner, I. G. (1999). The IDEA amendments of 1997: A school-wide model for conducting functional behavioral assessments and developing behavior intervention plans. Education \& Treatment of Children, 22, 244-266.

Gable, R. (1999). Functional assessment in school settings. Behavioral Disorders, 24, 246-248.

Jolivette, K., Barton-Arwood, S., \& Scott, T. M. (2000). Functional behavioral assessment as a collaborative process among professionals. Education \& Treatment of Children, 23, 298313.

Lane, M. D. (2002, March). Counselors' use of functional assessment: A survey of Pennsylvania counselors. Paper presented at the annual meeting of the American Counseling Association, New Orleans, LA.

Rogers, E. L. (2001). Functional behavioral assessment and children with autism: Working as a team. Focus on Autism and Other Developmental Disabilities, 16, 228-231.

Schmidt, 1. J. (2003). Counseling in the schools: Essential services and comprehensive programs (4th ed.). Boston: Allyn and Bacon.

Scott, T. C., \& Nelson, C. M. (1999). Functional behavioral assessment: Implications for training and staff development. Behavioral Disorders, $24,249-252$.

Villalba, J. A., \& Sheperis, S. (2004). Special education identification and process. In T. S. Watson \& C. H. Skinner (Eds.), Encyclopedia of school psychology (pp. 315-317). New York: Kluwer.

\section{AUTHORS' NOTE}

Address correspondence to José A. Villalba, Assistant Professor, Department of Counseling and Educational Development, The University of North Carolina at Greensboro, 221 Curry Building, School of Education, Greensboro, NC 27402. E-Mail: javillal@uncg.edu 